\title{
Vanadate increases glucocorticoid receptor-mediated gene expression: a novel mechanism for potentiation of a steroid receptor
}

\author{
Sergio Li Calzi, Sumudra Periyasamy, Da-Pei Li, Edwin R. Sánchez* \\ Department of Pharmacology, Medical College of Ohio, 3035 Arlington Avenue, Toledo, OH 43614-5804, USA
}

Accepted 5 October 2001

\begin{abstract}
Transition metal oxyanions, such as molybdate, tungstate and vandadate, have been shown to prevent in vitro hormone-induced activation of the glucocorticoid receptor (GR) by blocking dissociation of the GR/heat shock protein heterocomplex. In this work, we report a novel effect of vanadate: in vivo potentiation of $G R$-mediated gene expression. In cells stably-transfected with complex (mouse mammary tumor virus (MMTV)) or minimal GR-regulated CAT reporters, treatment with $500 \mu \mathrm{M}$ vanadate caused $C A T$ gene expression to dramatically increase, even at saturating concentrations of dexamethasone; while no such effect was seen in response to RU486 antagonist. Similar treatment with molybdate had no effect on GR activity, suggesting that the response to vanadate was not a general property of transition metal oxyanions. Treatment with vanadate after hormone-induced nuclear translocation of the GR also caused potentiation, demonstrating that vanadate was acting on a post-transformation event, perhaps by affecting the transactivation function of DNA-bound GR. Paradoxically, vanadate caused an apparent but temporary "loss" of GR protein immediately after treatment (as measured by loss of reactivity to BuGR2 antibody and of hormone-binding capacity) that returned to normal at approximately $8 \mathrm{~h}$ post-treatment, suggesting that potentiation of GR transactivation function (as measured by our CAT assays) was probably occurring during the later stages (8-24 h) of this assay. However, gel shift analyses revealed that vanadate could induce binding of the hormone-free GR to glucocorticoid response element (GRE)-containing oligonucleotides immediately after treatment. Thus, the rapid vanadate-induced "loss" of GR was not due to degradation of GR protein. Yet, vanadate in the absence of hormone had no effect on CAT reporter expression, demonstrating that this form of the GR still requires agonist for its enhanced transcriptional activity. As an indication of the potential mechanism of vanadate action, vanadate was found to dramatically stimulate the mitogen-activated protein kinases, ERK-1 and ERK-2. In addition, vanadate potentiation of $G R$ reporter gene expression was completely blocked by the tyrosine kinase inhibitor herbimycin A. Taken as a whole, our results suggest that vanadate can have dramatic and complex effects on GR structure and function, resulting in hormone-free activation of GR DNA-binding function, as well as alterations to the BuGR2 epitope and hormone-binding domains-while at the same time stimulating tyrosine phosphorylation pathways controlling GR-mediated gene transcription. () 2002 Elsevier Science Ltd. All rights reserved.
\end{abstract}

Keywords: Vanadate; Steroid receptor; Gene expression

\section{Introduction}

The glucocorticoid receptor (GR) is a hormone-dependent transcription factor that serves to positively or negatively regulate specific gene expression. In the absence of hormone, the GR is known to reside in the cytoplasm of most cells as a heteromeric complex containing the Hsp90-based chaperone complex (for a comprehensive review of this and related topics, see [1]). Based on this structure and localization, it is generally accepted that the major stages of the GR signaling pathway include the following sequence of events: hormone-binding, dissociation of the GR/Hsp complex, translocation to the nucleus of hormone-bound

\footnotetext{
${ }^{*}$ Corresponding author. Tel.: +1-419-383-4182; fax: +1-419-383-2871.

E-mail address: esanchez@mco.edu (E.R. Sánchez).
}

GR, binding by GR to high-affinity response elements within chromatin, and, finally, enhancement of Pol II-based transcription through mediation by co-activators.

As a result of numerous studies done under cell-free conditions, it has been suggested that sodium molybdate and other transition metal oxyanions (tungstate and vanadate) could be used to effectively block the second stage of this signal pathway, namely, hormone-induced dissociation of the GR heterocomplex (a process also referred to as "transformation"). In these studies, addition of molybdate, vanadate or tungstate to cytosols has been shown to prevent GR transformation, not only in response to hormone, but also in response to elevated temperatures, salt, or precipitation with heparin or ammonium sulfate [2-8]. Addition of molybdate after the transformation event has been shown to not cause re-association of the GR/Hsp90 complex, nor 
to prevent subsequent binding of GR to DNA [8], suggesting that these oxyanions act to prevent an irreversible step in the transformation process. Evidence suggests that the site of action for this effect is a low-affinity, ATP-binding site on Hsp90, as both vanadate and permolybdate can alter the conformation of purified Hsp90 in a manner similar to that seen with azido-ATP [9-12].

Although the above observations suggest that molybdate and similar compounds should be effective inhibitors of GR signaling in vivo, few reports exist to support this notion. In the original work of its kind, Samuels and co-workers showed that treatment of intact $\mathrm{GH}_{1}$ cells with $30 \mathrm{mM}$ sodium molybdate (presumably by simply adding molybdate to the medium) reduced the rate of nuclear accumulation of hormone-bound GR [13], as measured by fractionation studies of cells incubated with radiolabeled hormone. Yang and DeFranco used liposome-mediated delivery of molybdate into cells, achieved similar results by demonstrating that molybdate could block both hormone-induced dissociation of the GR/Hsp90 complex and nuclear import of GR [14]. In general, therefore, these limited in vivo studies support the mechanism of action proposed for these compounds under cell-free conditions, namely, stabilization of the GR heterocomplex against hormone-induced transformation.

Because of this history, we were recently surprised to find that vanadate treatment of intact cells can also have a stimulatory effect on GR activity. This was discovered as part of our efforts to use sodium vanadate to inhibit heat shock factor (HSF1) activity in stressed cells [15]. In that work, HSF1 inactivation was achieved through a mechanism that was consistent with the known ability of vanadate to act as an inhibitor of tyrosine phosphatases [16-18], resulting in subsequent inhibition of HSF1 via MAPK (ERK-2)-mediated phoshorylation $[19,20]$. However, in cells stably-transfected with a GR-responsive CAT reporter, we have observed that vanadate treatment under non-stress conditions greatly increases hormone-induced $C A T$ gene expression. This observation has led to the following question: Is potentiation of GR activity by vanadate mediated by an effect on the Hsp90-based chaperone complex or by a novel mechanism involving phosphorylation events controlling GR transactivation? In the course of addressing this question, we have uncovered an unusual and paradoxical mechanism in which vanadate initially causes a temporary loss of GR that is functional for hormone-binding and BuGR2 antibody reactivity, followed by a large increase in the transactivation function of DNA-bound GR. As these effects were not seen in cells treated with molybdate, and as the vanadate effect is seen for GR that has already undergone hormone-induced nuclear translocation, it is clear that vanadate potentiation is not operating via the traditional effects of these compounds at the untransformed GR heterocomplex. Instead, it appears that vandate potentiation of GR transactivation function is the result of phosphorylation mechanisms that either control the intrinsic activity of the DNA-bound GR, or the activity of the Pol II complex, including co-activators, that respond to GR.

\section{Results}

\subsection{Potentiation of GR-mediated reporter gene expression by sodium vanadate}

In previous work by our laboratory [15], studying the effects of heat shock on GR activity, we used sodium vanadate to inhibit HSF1 activity in stressed cells by a mechanism involving MAPK (ERK-1 and ERK-2)-mediated phosphorylation of HSF1 $[19,20]$. In those studies, the presumptive target of vanadate action was the dual-specificity MAPK phosphatase, MKP1, inhibition of which by vanadate has been shown to induce MAPK activity $[17,18]$. In the course of establishing control conditions for those experiments, we treated L929 cells stably-transfected with the pMMTV-CAT reporter (LMCAT2 cells) with vanadate in the expectation that this drug should either be neutral with respect to GR action, or should inhibit the GR-based on the well-documented effects of vanadate and similar oxyanions on GR activity in vitro [2-8] and in vivo [13,14]. To our surprise, neither outcome was observed. Instead, vanadate treatment of LMCAT2 cells resulted in a dose-dependent potentiation of dexamethasone-induced pMMTV-CAT expression (Fig. 1A), with increased activity seen with vanadate ranging from 50 to $500 \mu \mathrm{M}$. A potential explanation for this effect was that vanadate at these seemingly-high concentrations was actually a form of chemical shock, such as that seen with sodium arsenite, which we have previously shown will cause similar increases of GR activity in these same cells [21,22]. However, this mechanism was clearly not operating, as vanadate treatment $(500 \mu \mathrm{M})$ of L929 cells stably-transfected with an HSF1-responsive CAT reporter was found to inhibit heat and arsenite induction of HSF1 activity [15].

As the mouse mammary tumor virus (MMTV) promoter $(\approx 1200 \mathrm{bp})$ contains many potential binding sites for transacting factors other than GR (any one of which could be responsible for potentiation of GR action through cooperative binding at the promoter), we tested the effects of vanadate in cells stably-transfected with the minimal pGRE $_{2}$ EIB-CAT reporter (LGRECAT cells), in which CAT expression is solely controlled by two synthetic glucocorticoid response elements (GREs) and a TATA box [23]. In the experiments of Fig. 1B, LGRECAT cells were left untreated or were treated with $500 \mu \mathrm{M}$ vanadate prior to exposure to increasing concentrations of dexamethasone. The results show that vanadate potentiation of dexamethasone-induced CAT expression is concentration-dependent, with the largest increases occurring at $100 \mathrm{nM}$ and $1 \mu \mathrm{M}$ hormone. As maximal dexamethasone-induced CAT activity in these cells (in the absence of vanadate treatment) occurs at $1 \mu \mathrm{M}$ dexamethasone, it is apparent that vanadate treatment is a way in which latent activity on the part of GR can be unmasked. 
(A)
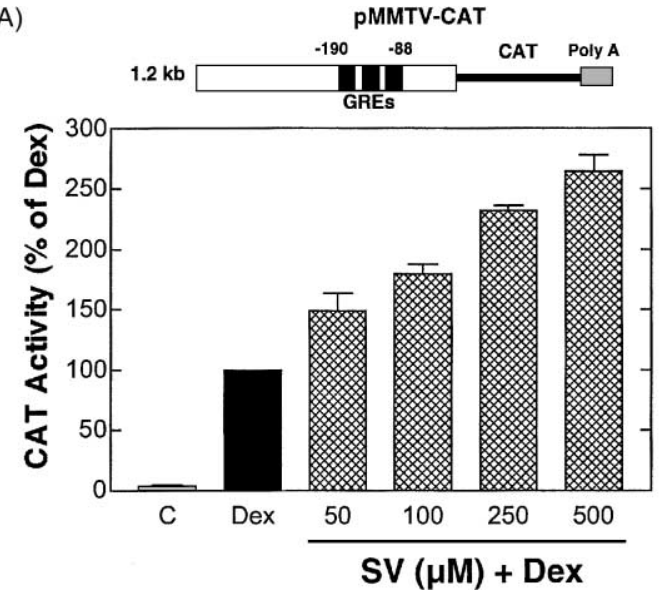

(B)
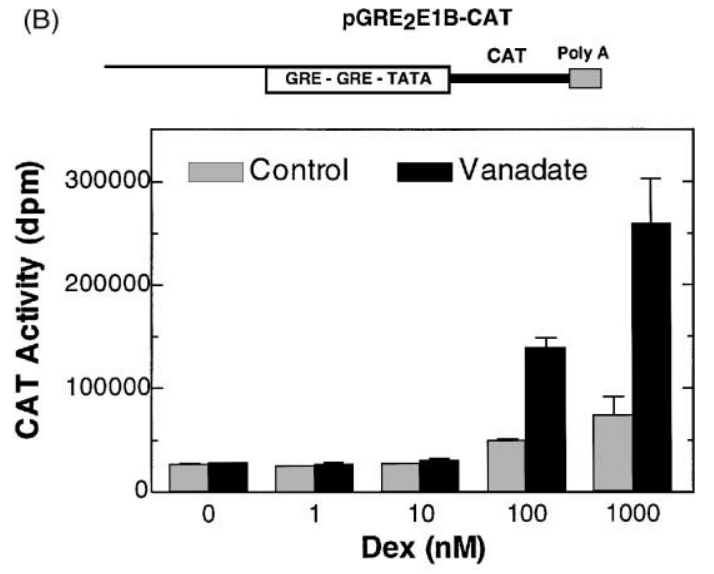

Fig. 1. Sodium vanadate increases GR-mediated $C A T$ gene expression controlled by complex and minimal promoters, even at saturating concentrations of dexamethasone. Panel A: L929 cells stably-transfected with a CAT reporter construct controlled by the complex MMTV-LTR promoter (LMCAT2 cells) were subjected to the indicated conditions prior to measurement of CAT activity. (C): no treatment; Dex: $1 \mu \mathrm{M}$ dexamethasone for $20 \mathrm{~h}$; SV + Dex: $50-500 \mu \mathrm{M}$ sodium vanadate for $2.5 \mathrm{~h}$ followed by washing and additional culture in the presence of $1 \mu \mathrm{M}$ dexamethasone for $20 \mathrm{~h}$. The results shown represent the means \pm S.E.M. of six independent experiments. Panel B: L929 cells stably-transfected with a CAT reporter construct controlled by the synthetic, $\mathrm{pGRE}_{2} \mathrm{E} 1 \mathrm{~B}$ minimal promoter (LGRECAT cells) were left untreated (light bars) or were treated with $500 \mu \mathrm{M}$ sodium vanadate for $2.5 \mathrm{~h}$ (dark bars). After washing, cells were incubated with increasing concentrations of dexamethasone for $20 \mathrm{~h}$ followed by measurement of CAT activity. The results shown represent the mean \pm S.E.M. of three independent experiments.

More importantly, the results also demonstrate that the vanadate effect cannot be explained by the involvement of any other transacting factor, suggesting that unmasking of this latent activity requires only GR, or non-DNA-binding factors controlling GR action.

To further characterize the hormone requirements of this response, we tested whether potentiation of GR by vanadate could also be seen in the presence of RU486 antagonist (Fig. 2A). As expected, vanadate treatment caused a dramatic increase in dexamethasone-induced CAT expression, while RU486 alone had no effect on GR transactivity. In cells exposed to vanadate and RU486, an increase in the RU486 response was observed. However, the magnitude of
CAT activity under this condition was still much lower than that seen with dexamethasone + vanadate. We conclude, therefore, that vanadate cannot dramatically overcome the antagonist activity of RU486 and that vanadate's action as a potentiator requires agonist-bound receptor.

As stated earlier, the vast preponderance of evidence suggests that vanadate, like molybdate, should act to block hormone-induced transformation of GR heterocomplexes, leading to a blockade of all downstream events. Yet, in our system, vanadate appears to have the opposite effect, suggesting that this drug is acting by a distinct mechanism. If so, we were interested to know if sodium molybdate also behaved like vanadate in our system. To test this, we prepared
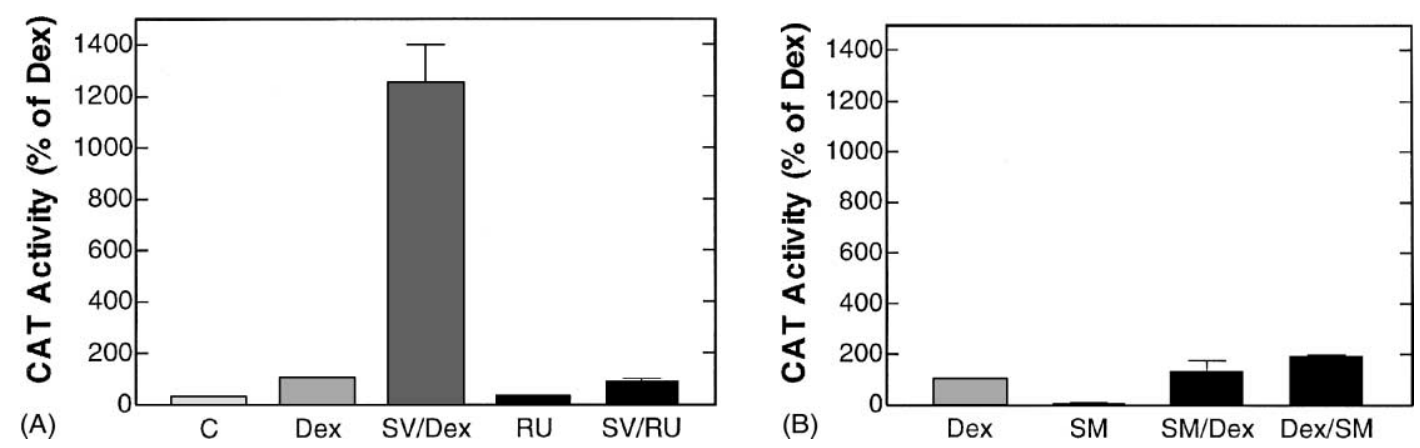

Fig. 2. Vanadate potentiation of GR-mediated CAT expression is agonist specific and does not occur with sodium molybdate. Panel A: LGRECAT cells were subjected to the indicated conditions followed by assay for CAT activity. The results shown represent the mean \pm S.E.M. of four independent experiments. (C): no treatment; Dex: $1 \mu \mathrm{M}$ dexamethasone for $20 \mathrm{~h}$; SV/Dex: $500 \mu \mathrm{M}$ sodium vanadate for $2.5 \mathrm{~h}$ followed by washing and culture in the presence of $1 \mu \mathrm{M}$ dexamethasone for $20 \mathrm{~h}$; RU: $1 \mu \mathrm{M}$ RU486 for $20 \mathrm{~h}$; SV/RU: $500 \mu \mathrm{M}$ sodium vanadate for $2.5 \mathrm{~h}$ followed by washing and culture in the presence of $1 \mu \mathrm{M}$ RU486 for $20 \mathrm{~h}$. Panel B: LGRECAT cells were treated as above, except that $500 \mu \mathrm{M}$ sodium molybdate (SM) was used. The results shown represent the mean \pm S.E.M. of two independent experiments. (C): no treatment; Dex: $1 \mu \mathrm{M}$ dexamethasone for $20 \mathrm{~h}$; SM/Dex: $500 \mu \mathrm{M}$ sodium molybdate for $2.5 \mathrm{~h}$ followed by washing and culture in the presence of $1 \mu \mathrm{M}$ dexamethasone for $20 \mathrm{~h}$; Dex/SM: $1 \mu \mathrm{M}$ dexamethasone for $2 \mathrm{~h}$ followed by $500 \mu \mathrm{M}$ sodium molybdate for $2.5 \mathrm{~h}$, washing, and culture in the presence of $1 \mu \mathrm{M}$ dexamethasone for $20 \mathrm{~h}$. 
stocks of molybdate in the same manner as our active sodium vanadate solutions, followed by treatment of LGRECAT cells (Fig. 2B). The results show that pretreatment of cells with $500 \mu \mathrm{M}$ sodium molybdate has little or no effect on GR-mediated CAT expression, especially when compared to vanadate at the same concentration (Figs. 1B and 2A). Thus, vanadate, as used in this study, appears to be operating by a mechanism not involving the typical actions of transition metal oxyanions to stabilize GR heterocomplexes.

\subsection{Vanadate alters GR conformation, leading to temporary loss of BuGR2 antibody reactivity and hormone-binding function}

As an initial test of the mechanism by which vanadate causes potentiation of the GR, we attempted to measure the effects of vanadate on GR nuclear translocation. This was done by fractionation of cells, followed by immunepurification and Western-blot analysis using the BuGR2 monoclonal antibody against GR (Fig. 3). As expected, the results show that hormone-free GR is predominantly found in the cytosolic fraction of cells, while hormone treatment ( $1 \mu \mathrm{M}$ Dex, $1 \mathrm{~h}$ ) results in GR that is predominantly in the nuclear fraction (Fig. 3A). To our surprise, however, vanadate treatment resulted in no detectable GR. This ability of vanadate to apparently cause a complete loss of GR protein was highly consistent and could be seen whether cells were treated with vanadate alone (SV condition), or treated with vanadate either before or after exposure to hormone (see SV/Dex and Dex/SV conditions of Fig. 3A). The latter condition was particularly interesting, as it suggested that vanadate was causing "loss" of GR after it had already translocated to the nucleus (compare with Dex condition). However, one possible explanation for this result was that vanadate was somehow causing the GR to become tightly bound within the nucleus, even in the absence of hormone. The experiments of Fig. 3A used salt extraction $(400 \mathrm{mM}$ $\mathrm{NaCl}$ ) to remove $\mathrm{GR}$ from the nuclear pellet. As a more stringent means by which to extract GR, we used a method involving solubilization of nuclei with SDS (Fig. 3B). Here, also the results were the same-lack of BuGR2-reactive GR following vanadate treatment.

Based on these data, it seemed highly unlikely that tight nuclear binding was responsible for these results. Instead, the most logical hypothesis was that vanadate was simply causing loss of GR through degradation. However, if degradation of GR was occurring, it had to be operating for both the hormone-free GR present in the cytoplasm and the hormone-bound GR localized to the nucleus (Fig. 3A). Moreover, vanadate-induced "loss" of GR was observed immediately after the $2.5 \mathrm{~h}$ vanadate treatment (Fig. 3A), suggesting a faster-acting mechanism than that typically associated with degradative processes. To measure exactly how fast vanadate was acting on the GR, we subjected LGRECAT cells to a time-course of exposure to vanadate, followed by measurement of GR reactivity to BuGR2 antibody in cytosols (Fig. 3C). The results show a complete loss of BuGR2-reactive GR within 30 min of vanadate treatment. Thus, this effect of vanadate on the GR is very rapid.

Given these results, we decided to test the possibility that vanadate was simply causing an alteration of the BuGR2 epitope, making it unreactive to antibody. If true, this mechanism would mean that we should be able to label the GR by other means, such as through use of radio-labeled ligand. As our first test of this, we incubated cytosols from control and vanadate-treated cells with the covalent ligand, $\left[{ }^{3} \mathrm{H}\right]$ dexamethasone 21-mesylate (Fig. 4). Once more the results were unexpected-loss of mesylate-labeled GR in

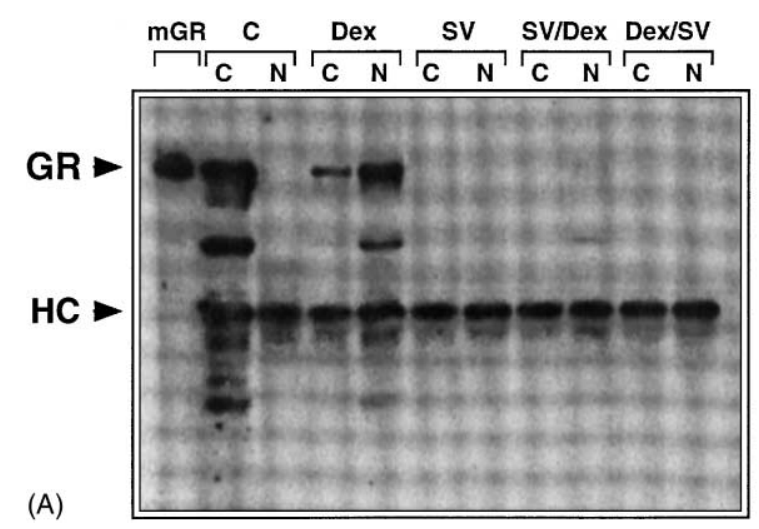

(B)

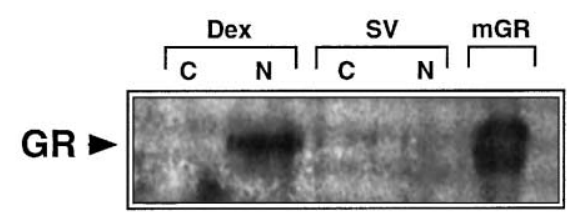

SV (min): $\quad \begin{array}{lllll}0 & 15 & 30 & 60 & 120\end{array}$

(C)

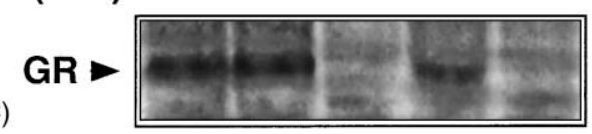

Fig. 3. Vanadate causes rapid loss of BuGR2-reactive GR. Panel A: LGRECAT cells subjected to the indicated conditions were fractionated into cytosolic (C) and nuclear $(\mathrm{N})$ portions by salt extraction followed by immunoadsorption of GR and Western-blotting using BuGR2 antibody, see text. Results are representative of five independent experiments. mGR: baculovirus-expressed mouse GR; (C): no treatment; Dex: $1 \mu \mathrm{M}$ dexamethasone for $1 \mathrm{~h}$; SV: $500 \mu \mathrm{M}$ sodium vanadate for $2.5 \mathrm{~h}$; SV/Dex: $500 \mu \mathrm{M}$ sodium vanadate for $2.5 \mathrm{~h}$ followed by $1 \mu \mathrm{M}$ dexamethasone for $1 \mathrm{~h}$; Dex/SV: $1 \mu \mathrm{M}$ dexamethasone for $1 \mathrm{~h}$ followed by $500 \mu \mathrm{M}$ sodium vanadate for $2.5 \mathrm{~h}$; HC $=\mathrm{IgG}$ heavy chain. Panel B: LGRECAT cells were fractionated as in Panel A, except GR was extracted by SDS followed by immunoadsorption of GR and Western-blotting using BuGR2 antibody. Dex: $1 \mu \mathrm{M}$ dexamethasone for $1 \mathrm{~h}$; SV: $500 \mu \mathrm{M}$ sodium vanadate for $2.5 \mathrm{~h}$; mGR: baculovirus-expressed mouse GR. Panel C: LGRECAT cells were incubated with $500 \mu \mathrm{M}$ vanadate for 0 , 15,30 , 60 and $120 \mathrm{~min}$ followed by preparation of cytosolic extracts containing equal protein and Western-blotting with BuGR2 antibody. Results are representative of two independent experiments. 


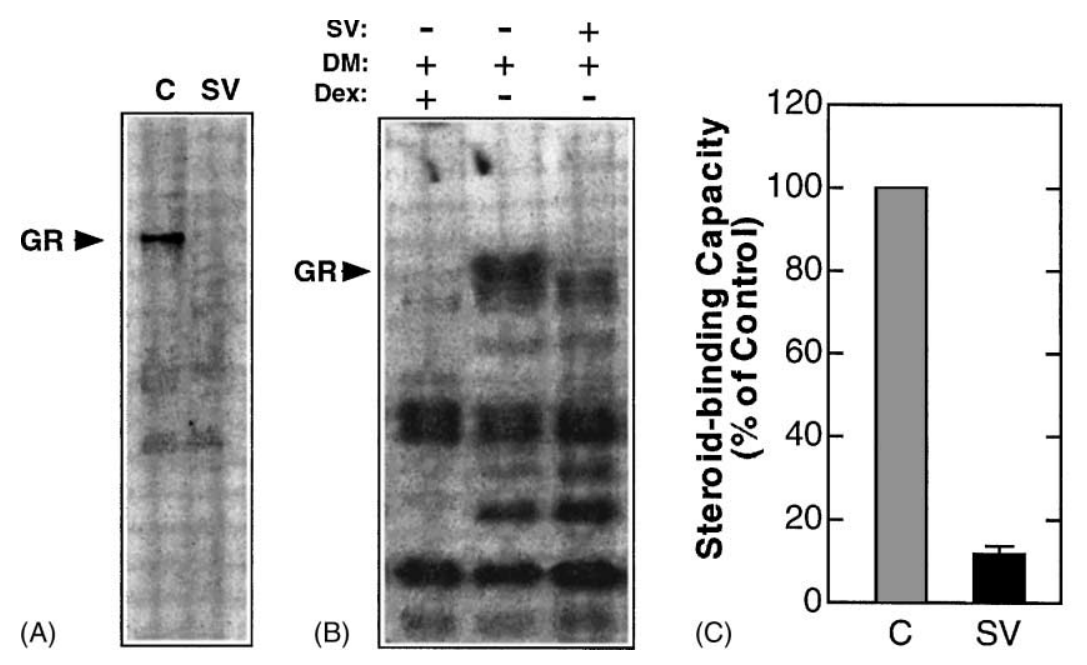

Fig. 4. Vanadate causes loss of GR binding to covalent agonist, ${ }^{3} \mathrm{H}$ ]dexamethasone 21-mesylate, and loss of hormone-binding capacity in vivo. Cytosols were prepared from LGRECAT cells untreated (C) or treated with $500 \mu \mathrm{M}$ sodium vanadate for $2.5 \mathrm{~h}(\mathrm{SV})$. Panel A: Western-blot of cytosols containing equal protein using BuGR2 antibody as probe. Panel B: cytosols from vanadate-treated $(+\mathrm{SV})$ and control $(-\mathrm{SV})$ cells were incubated with $200 \mathrm{nM}$ $\left[{ }^{3} \mathrm{H}\right]$ dexamethasone 21 -mesylate $(\mathrm{DM})$ for $4 \mathrm{~h}$ on ice, in the presence $(+)$ or absence $(-)$ of radioinert dexamethasone $(10 \mu \mathrm{M})$. Binding was stopped by addition of $2 \times$ SDS sample buffer and boiling, followed SDS-PAGE and autoradiography utilizing Amplify ${ }^{\circledR}$ fluorography reagent (Amersham). The autoradiogram was exposed for 30 days. Results are representative of four independent experiments. Panel C: LGRECAT cells were left untreated (C) or were treated with $500 \mu \mathrm{M}$ sodium vanadate (SV) for $2.5 \mathrm{~h}$, followed by measurement of in vivo hormone-binding capacity, using [ $\left.{ }^{3} \mathrm{H}\right] \mathrm{dexamethasone}$. The results shown represent the mean \pm S.E.M. of four independent experiments.

response to vanadate. As this experiment was performed on cytosolic preparations, it remained a possibility that lack of mesylate binding in the cytosol in response to vanadate was because GR with altered BuGR2 epitope had translocated to the nucleus. For this reason, we performed the whole-cell hormone-binding assays seen in Fig. 4C. In this case, vanadate-treated cells were incubated with $\left[{ }^{3} \mathrm{H}\right]$ dexamethasone for $2 \mathrm{~h}$ at $37^{\circ} \mathrm{C}$ followed by measurement of specific hormone-binding capacity. The results show a near-complete loss of in vivo GR hormone-binding function in response to vanadate treatment.

At this point, it was clear that vanadate treatment of cells was causing a loss of GR hormone-binding function that correlated with an apparent loss of GR protein. If true, how was it possible for vanadate to also cause potentiation of the GR response? As we have shown that vandate potentiation of GR requires agonist-bound receptor, we reasoned that the inhibition of hormone-binding function by vanadate had to be temporary. In other words, GR hormone-binding function had to return during the typical $20 \mathrm{~h}$ period of post-treatment incubation employed in our reporter gene experiments. With this in mind, we measured GR hormone-binding and BuGR2 antibody reactivity during time-courses of "recovery" from vanadate treatment (Fig. 5). It can be seen that both of these functions return to normal or near-normal levels during the recovery period. In the case of steroid-binding capacity (SBC) (Fig. 5A), approximately $50 \%$ of this function is recovered $16 \mathrm{~h}$ after vanadate treatment, while approximately $100 \%$ of BuGR2-reactivity returns within $8 \mathrm{~h}$ (Fig. 5A). Interestingly, return of BuGR2-reactive GR was observed in the cytosolic fraction in response to vanadate treatment alone (Fig. 5A), but was localized to the nuclear pellet fractions when hormone was present during the recovery period (Fig. 5B), suggesting that GR which has recovered its steroid-binding function also recovers the ability to undergo transformation and conversion to the DNA-binding state.

\subsection{Vanadate activates DNA-binding by the hormone-free $G R$ and potentiates the transactivation function of the DNA-bound, agonist-activated receptor}

To this point, our results suggest that vanadate is causing rapid but temporary changes in GR conformation, leading to functional alterations in both the steroid-binding and BuGR2-reactive domains. But, are these the only alterations in GR function that result from vanadate treatment? As a test of one more GR function, we performed the GR electrophoretic mobility shift assay (EMSA) experiments seen in Fig. 6. Here, the results were aso surprising, as vanadate treatment of intact cells was found to cause activation of DNA-binding function by the hormone-free GR. DNA-bound GR was also recovered following combined vanadate and hormone treatment. Given that these assays were performed immediately after the $2.5 \mathrm{~h}$ vanadate treatment, it is now clear that vanadate is not causing loss of GR hormone-binding function and of the BuGR2 epitope through a process of degradation. Rather, this treatment is having dramatic and complex effects on multiple aspects of GR regulation. In particular, the EMSA data would suggest that vanadate treatment in the absence of hormone can cause both transformation of the GR heterocomplex and nuclear translocation of the hormone-free GR, as these 
(A)

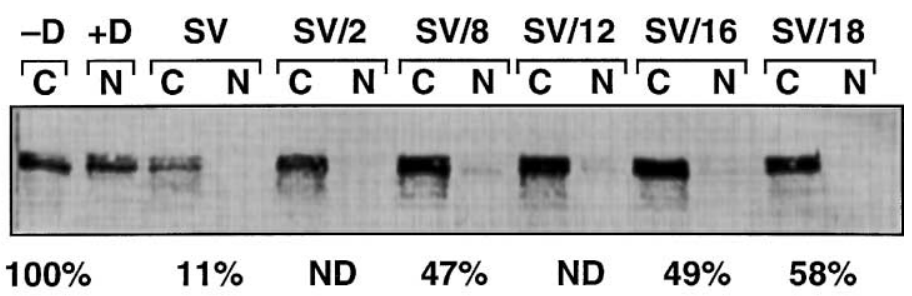

(B)

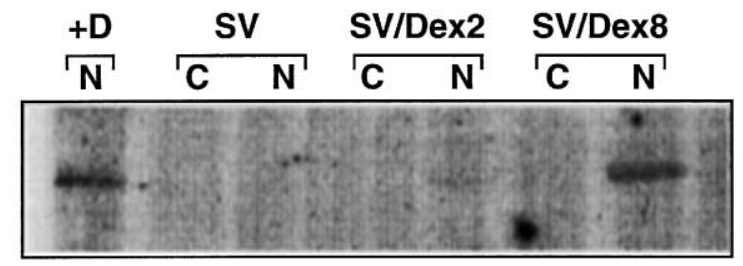

Fig. 5. Loss and recovery of GR SBC and BuGR2 antibody reactivity during a sodium vanadate post-treatment time-course. LGRECAT cells were subjected to the indicated conditions, followed by measurement of in vivo SBC or Western-blot analysis of GR in cytosolic (C) and nuclear (N) fractions. Panel A: effect of vanadate on BuGR2-reactivity and SBC during hormone-free recovery. $(-\mathrm{D})$ : no treatment; $(+\mathrm{D})$ : $1 \mu \mathrm{M}$ dexamethasone for $1 \mathrm{~h}$; SV: $500 \mu \mathrm{M}$ sodium vanadate for $2.5 \mathrm{~h}$; SV/2 through 18: $500 \mu \mathrm{M}$ sodium vanadate for $2.5 \mathrm{~h}$ followed by washing and recovery in the absence of hormone for $2,8,12,16$ and $18 \mathrm{~h}$. SBC results represent the mean \pm S.E.M. of two independent experiments. Western-blot results are representative of two independent experiments. Panel B: effect of vanadate on BuGR2-reactivity during recovery in the presence of hormone. $(+\mathrm{D})$ : $1 \mu \mathrm{M}$ dexamethasone for $1 \mathrm{~h}$; SV: $500 \mu \mathrm{M}$ sodium vanadate for $2.5 \mathrm{~h} ; \mathrm{SV} / 2$ and $8: 500 \mu \mathrm{M}$ sodium vanadate for $2.5 \mathrm{~h}$ followed by washing and recovery in the presence of $1 \mu \mathrm{M}$ dexamethasone for 2 and $8 \mathrm{~h}$.
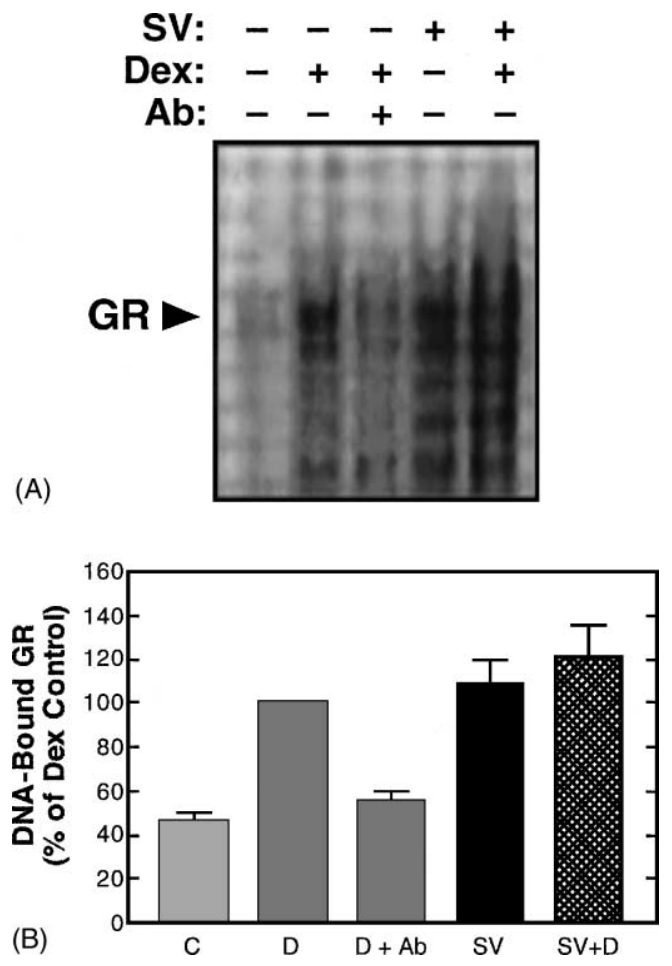

Fig. 6. Sodium vanadate activates DNA binding by the hormone-free GR. LGRECAT cells were subjected to the indicated conditions followed by preparation of nuclear extracts and EMSA assay for GR DNA-binding. (C): no treatment; (D): $1 \mu \mathrm{M}$ dexamethasone for $1 \mathrm{~h}$; D+Ab: $1 \mu \mathrm{M}$ dexamethasone for $1 \mathrm{~h}$, followed by incubation of nuclear extracts with BuGR2 antibody against GR prior to EMSA assay; SV: $500 \mu \mathrm{M}$ sodium vanadate for $2.5 \mathrm{~h}$; SV/Dex: $500 \mu \mathrm{M}$ sodium vanadate for $2.5 \mathrm{~h}$ followed by $1 \mu \mathrm{M}$ dexamethasone for $1 \mathrm{~h}$. Panel A: autoradiogram of typical results. Arrow indicates major band corresponding to oligo-bound GR. Panel B: quantitation of results by densitometric scanning of the autoradiograms. The results shown represent the mean \pm S.E.M. of 11 independent experiments.
EMSA assays were performed solely on nuclear extracts. Vanadate-induced transformation of the GR heterocomplex would be consistent with the ability of vanadate to cause loss of GR hormone-binding function (Fig. 4), since a large number of reports support a model in which GR interaction with Hsp90 is required for maintenance of receptor steroid-binding function (see [1]).

Based on the above, it is appears that vanadate is having multiple and, seemingly, diametrically-opposed actions on GR function-temporary loss of hormone-binding, yet increased $G R$-mediated reporter gene activity. In an attempt to clarify how vanadate was increasing GR-mediated tran-

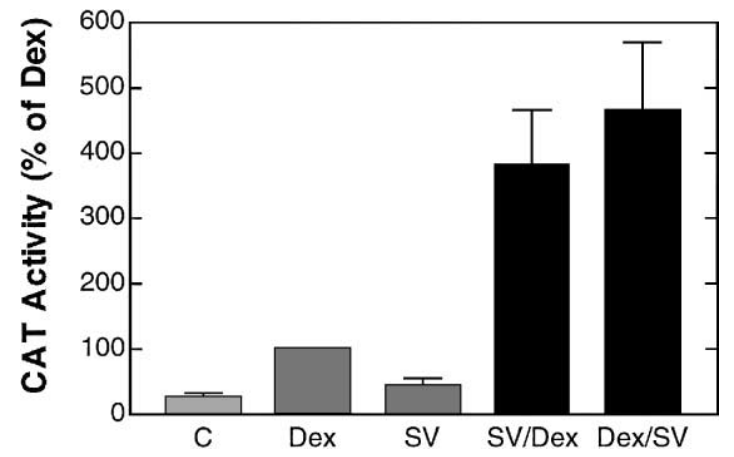

Fig. 7. Sodium vanadate increases GR-mediated CAT expression both before and after agonist-induced activation of the receptor. LGRECAT cells were subjected to the indicated conditions followed by assay for CAT activity. The results shown represent the mean \pm S.E.M. of $8-12$ independent experiments. (C): no treatment; Dex: $1 \mu \mathrm{M}$ dexamethasone for $20 \mathrm{~h}$; SV: $500 \mu \mathrm{M}$ sodium vanadate for $2.5 \mathrm{~h}$; SV/Dex: $500 \mu \mathrm{M}$ sodium vanadate for $2.5 \mathrm{~h}$ followed by washing and culture in the presence of $1 \mu \mathrm{M}$ dexamethasone for $20 \mathrm{~h}$; Dex/SV: $1 \mu \mathrm{M}$ dexamethasone for $2 \mathrm{~h}$ followed by $500 \mu \mathrm{M}$ sodium vanadate for $2.5 \mathrm{~h}$, washing, and culture in the presence of $1 \mu \mathrm{M}$ dexamethasone for $15.5 \mathrm{~h}$. 
scription, we decided to test if the potentiation effect of vanadate on GR-induced CAT activity could be seen after hormone-induced activation of the receptor. In other words, does vanadate increase GR activity when it is already bound with hormone and to its high-affinity sites within promoters? To achieve this, we subjected LGRECAT cells to vanadate treatment either before or after incubation with hormone treatment (Fig. 7). The results show approximately the same level of potentiation of GR-mediated CAT expression by vanadate, regardless of order of addition. As the conditions of hormone treatment used in this experiment ( $1 \mu \mathrm{M}$ Dex for $2 \mathrm{~h}$ ) result in near-complete translocation of GR to the nucleus (Fig. 3), and as return of BuGR2-reactive GR in cells subjected to both vanadate and dexamethasone treatment occurs in the nucleus (Fig. 5), potentiation of GR by vanadate after hormone treatment suggests that vanadate is either affecting the intrinsic transactivation function of hormone-activated GR, or is affecting elements of the Pol II/co-activator transcription complex that responds to DNA-bound GR. Whether the other vanadate-induced
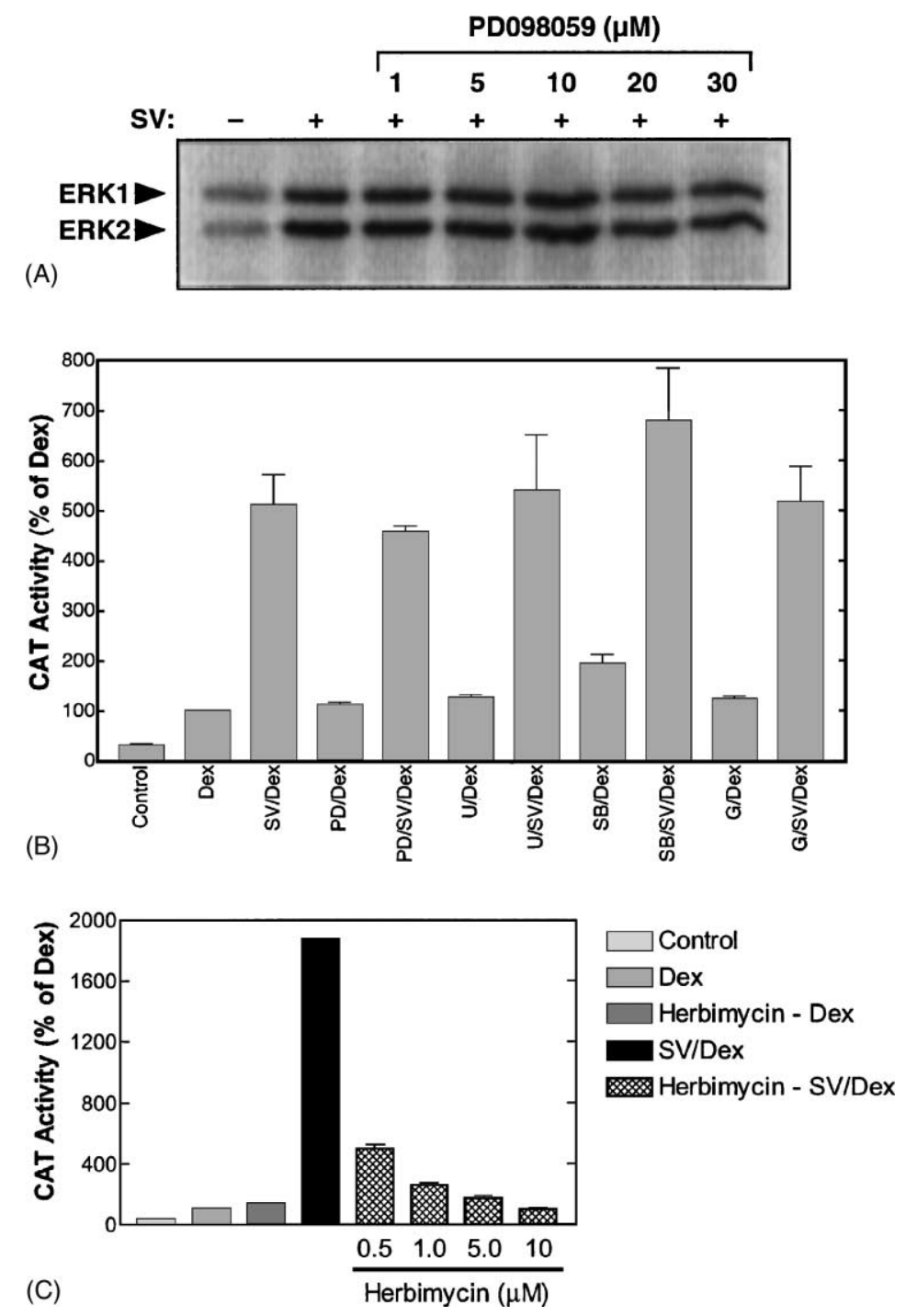

Fig. 8. Sodium vanadate activates ERK-1 and ERK-2 and vanadate potentiation of GR-mediated CAT expression is specifically blocked by the tyrosine kinase inhibitor herbimycin A. Panel A: vanadate activation of MAPK is not inhibited by PD098059. LGRECAT cells were treated with $500 \mu \mathrm{M}$ sodium vanadate $(\mathrm{SV})$ for $2.5 \mathrm{~h}$ in the presence or absence of the indicated concentrations of PD098059. Aliqouts of WCE containing equal protein were then blotted with the SC-7383 antibody recognizing the active forms of ERK-1 and ERK-2. Panel B: effects of various kinase inhibitors on vanadate potentiation of GR transactivation. LGRECAT cells were treated with $1 \mu \mathrm{M}$ dexamethasone for $20 \mathrm{~h}$ (Dex), or $500 \mu \mathrm{M}$ sodium vanadate for $2.5 \mathrm{~h}$ prior to dexamethasone treatment (SV/Dex) followed by assay for CAT activity. In addition, replicate flasks were preincubated with the indicated inhibitor for $3 \mathrm{~h}$ prior to the Dex or SV/Dex conditions. PD: $50 \mu \mathrm{M}$ PD098059; U: $50 \mu \mathrm{M}$ U0126; SB: $5 \mu \mathrm{M}$ SB203580; (G): $100 \mu \mathrm{M}$ genistein. The results shown represent the mean \pm S.E.M. of three independent experiments. Panel C: vanadate potentiation of GR transactivation is inhibited by herbimycin A. LGRECAT cells were treated as above, except for preincubation with herbimycin A for $3 \mathrm{~h}$, as indicated. The results shown represent the mean \pm S.E.M. of three independent experiments. Due to the magnitude of the vanadate potentiation in this experiment, data representing the control, Dex and herbimycin-Dex conditions are duplicated in the inset. 
changes in GR function (hormone-binding function and BuGR2-reactivity) play a role in the potentiation mechanism is still not clear, as these early changes, especially the altered reactivity to BuGR2 antibody, may contribute to increased transcriptional activity that can only be detected at the later time at which our CAT assays are performed.

\subsection{Vanadate activates MAPK and vanadate potentiation of GR transactivity is blocked by the tyrosine kinase inhibitor herbimycin A}

Given the well-documented role of vanadate as an inhibitor of protein phosphatases, we set out to test the role of protein phosphorylation in the mechanism by which this compound increases GR transactivity. As an initial test of this idea, we measured activation of the ERK-1 and ERK-2 MAPK family members through use of an antibody against the active, phosphorylated forms of these enzymes. In the Western-blot experiment of Fig. 8A, it can be seen that vanadate treatment of the LGRECAT cells dramatically increases the amounts of active ERK-1 and ERK-2. In the hopes that an inhibitor of ERK could, therefore, be used to determine the involvement of these kinases in the vanadate potentiation of GR, we tested whether vanadate activation of ERK-1 and ERK-2 could be blocked by the MAPK inhibitor PD098059. These results are also seen in the blot of Fig. 8A and demonstrate that PD098059 has no effect on this response. As the principal target of PD098059 is known to be MAPK kinase (the immediate upstream regulator of MAPK; also known as MEK), these results may simply indicate that vanadate activation of MAPK (presumably through inhibition of phosphatases, such as MKP1) is an event that is downstream and, consequently, independent of MAPK kinase activity.

As a way in which to screen for other potential inhibitors, we used our CAT assay to measure the effects of various inhibitors on vanadate potentiation of GR-mediated CAT gene expression (Fig. 8B). It can be seen that PD098059 had no effect on this response-a result that was consistent with the inability of this compound to block vanadate activation of ERK-1 and ERK-2. A more selective and potent inhibitor of MAPK kinase, U0126, also had no effect. Similarly, no effect was seen in response to treatment with SB203580 (a selective p38 kinase inhibitor) or with genistein (a non-selective tyrosine kinase inhibitor). However, inhibition of the vanadate effect on GR transactivity was seen in response to pretreatment of the LGRECAT cells with herbimycin A (Fig. 8C). These results show a concentration-dependent effect of herbimycin A on this response, with $10 \mu \mathrm{M}$ drug showing $100 \%$ inhibition. Interestingly, $0.5 \mu \mathrm{M}$ drug caused approximately $70 \%$ inhibition, suggesting that even lower concentrations of this compound would still be efficacious. Of importance is the fact that herbimycin A had no inhibitory effect on GR activity in the absence of vanadate (Dex alone), suggesting that herbimycin A was principally counter-acting the effect of vanadate, rather than affecting the GR mechanism itself. As will be discussed in more detail later, this observation is also important as it indicates that herbimycin $\mathrm{A}$ is not

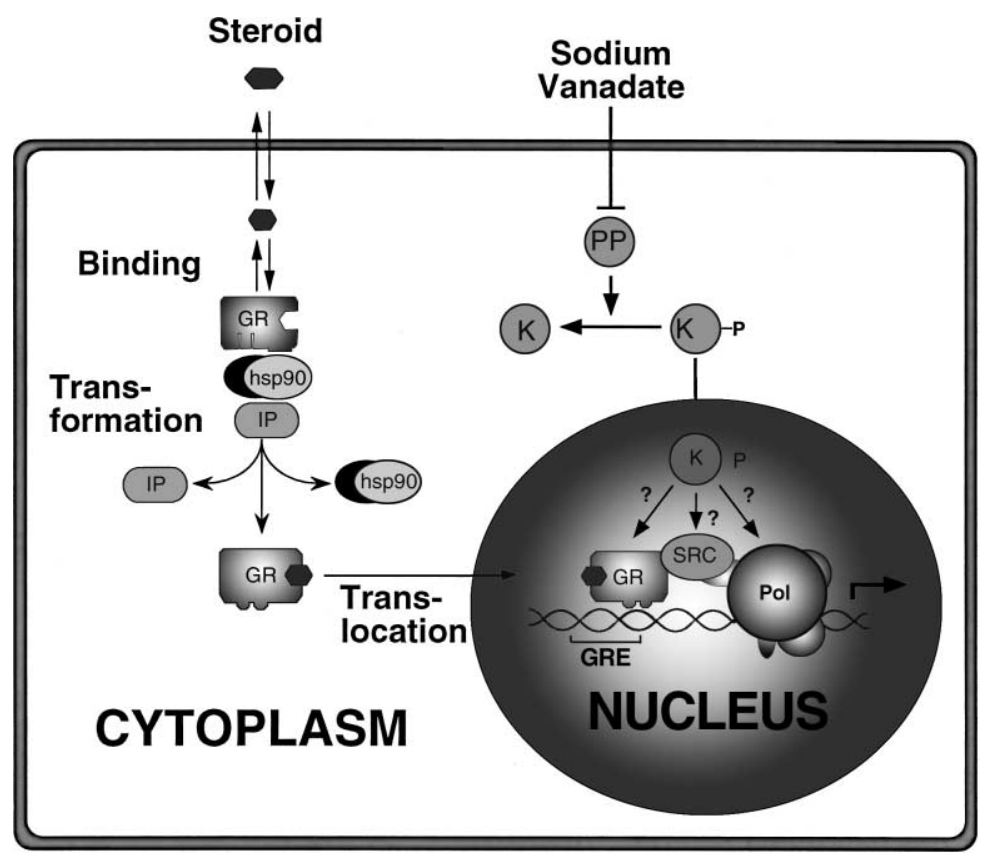

Fig. 9. Model for potentiation of $G R$-mediated gene expression by sodium vanadate. We have shown that potentiation of $G R$-mediated reporter gene expression by sodium vanadate does not result from stabilization of the GR/Hsp 90 heterocomplex. Rather, it is a process that occurs after agonist-induced nuclear translocation of the receptor and that can be completely blocked by tyrosine kinase inhibitor (herbimycin A). Based on these results, we propose that vanadate potentiation of GR occurs through phosphorylation events that target the GR or elements of the Pol II/co-regulator transcription complex that interact with DNA-bound GR. 
targeting Hsp90, as has been demonstrated in some systems $[24,25]$ but, rather, is most likely acting through its accepted role as a tyrosine kinase inhibitor.

\section{Discussion}

Most of the early discoveries concerning the structure of hormone-free steroid receptors would not have been possible without the use of sodium molybdate and related oxyanions as a means by which to stabilize receptor complexes during purification. In addition to this use, transitional metal oxyanions have also been used to prevent transformation of receptor heterocomplexes in response to hormone or a variety of other in vitro conditions. Based on these observations, it has been generally accepted that transition metal oxyanions should act as inhibitors of steroid receptor signaling within the intact cell. In this study, we show that the expected effect of these compounds is not seen under in vivo conditions. Instead, we demonstrate that sodium vanadate has a stimulatory effect on the transcriptional enhancement activity of hormone-bound GR.

Because potentiation of GR-mediated CAT gene expression by vanadate was not as expected, it seemed unlikely that vanadate was acting by targeting the Hsp90-based chaperone complex. Several of our observations support this conclusion. First, a similar effect on GR-mediated CAT gene expression was not seen in response to sodium molybdate (Fig. 2), even though molybdate was prepared in the same manner as our active vanadate solutions. It should be pointed out here that even vanadate has no activity on the GR of L929 cells when the stock solutions are not prepared by boiling at $\mathrm{pH} 10$ (data not shown). Thus, it is the monomeric form of vanadate, rather than decavanadate and other oligomeric forms, that is essential for activity - a result that is consistent with the use of these compounds as phosphatase inhibitors [16]. Second, potentiation of GR transactivity occurred both before and after hormone-induced translocation of the GR to the nucleus (Figs. 3 and 7). Thus, vanadate was clearly having an effect on GR that had, not only undergone dissociation from Hsp90, but had already become bound to high-affinity sites within chromatin. Third, vanadate caused an immediate loss (followed by recovery) of GR hormone-binding capacity in vivo (Figs. 4 and 5) - a result that is not consistent with the known ability of these compounds to stabilize the GR heterocomplex against loss of this function [26,27].

Based on the above, it appears that vanadate targets a stage of GR action that is distal to transformation of the GR/ Hsp90 heterocomplex (Fig. 9). Although our data indicates that vanadate may achieve this through a phosphorylation mechanism (see following sections for discussion), it is not certain that vanadate entry into the cell is required for this effect. In the earliest experiments of this kind, Samuels and co-workers [13] were able to inhibit GR transformation and translocation by apparently adding molybdate to the medium of $\mathrm{GH}_{1}$ cells, although no mention was made of how the molybdate stocks were prepared. A short time after that publication, we tried to duplicate their results by addition of various concentrations of molybdate to intact L929 cells - to no avail. Instead, we now find that only vanadate that is prepared to yield a high proportion of monomers $\left(\mathrm{Na}_{3} \mathrm{VO}_{4} \cdot n \mathrm{H}_{2} \mathrm{O}\right)$ has any effect on the GR of these cells. Although vanadate prepared in this fashion has been used to target various enzymatic activities within cells [16], especially tyrosine phosphatases $[17,18]$, proof that this action requires intracellular entry, rather than a membrane-based signaling event, has not, to our knowledge, been reported. Yet, studies using vanadate to inhibit intracellular phosphatases typically use very high concentrations of this compound $(100-500 \mu \mathrm{M})$, perhaps because it is inefficient in gaining entry into the cell. Indeed, the actual effective intracellular concentration of vanadate in our system is at present unknown. It is interesting to note that Defranco and co-workers, in a study of the in vivo effects of molybdate on the GR [14], used liposome-mediated delivery of molybdate into the cells, presumably because simple addition of the compound to the culture medium was ineffective. In that work, the authors report that molybdate could effectively block hormone-induced transformation and translocation of the GR. Thus, once inside the cell, molybdate, at least, appears to act much as it does in vitro.

If vanadate, in our system, is not affecting GR transactivation function through the Hsp90-based chaperone complex, what is its mechanism of action? Because vanadate alters BuGR2 antibody reactivity, it is tempting to speculate that this may occur through modification of the BuGR2 epitope, perhaps as a result of phosphorylation. However, the very changes that are induced in GR structure/function by vanadate have made a direct test of this hypothesis difficult, as our standard antibody or steroid-affinity purification techniques would not be effective on this form of the GR. Yet, other aspects of our data also point to a role for phosphorylation events in the vanadate response. Clearly, vanadate at the concentrations we employ can dramatically increase MAPK activity, particularly that of ERK-2 (Fig. 8). More importantly, potentiation of the GR by vanadate was completely blocked by herbimycin A-a widely-used tyrosine kinase inhibitor. It should be noted that the concentrations of herbimycin A employed $(0.5-10 \mu \mathrm{M})$ had no obvious cytotoxic effects on these cells. Curiously, genistein, another widely-used tyrosine kinase inhibitor did not inhibit the vanadate effect on GR. Although it is not clear why this discrepancy should occur, it is true that these compounds have very distinct modes of action, with herbimycin A having a benzoquinone moiety that is thought to covalently bind target kinase enzymes at thiol groups [28]. Moreover, similar discrepancies between herbimycin A and genistein have been reported, especially with respect to the actions of transcription factors. In one such report, the stimulatory effect of herbimycin A on constitutive (non-stress) expression of heat shock proteins was not observed following 
similar treatment with genistein [29]. Recent reports have shown that both herbimycin A and geldanamycin (another benzoquinone antibiotic) can bind $\mathrm{Hsp} 90$ and inactivate its activity as a molecular chaperone. Based on this property, both compounds have been found to specifically inhibit the protein tyrosine kinase, pp60v-src, by preventing its normal interaction with Hsp90 [24], while geldanamycin has been shown to inhibit GR signaling in a similar fashion [25]. However, our data does not support this mechanism of action, as herbimycin A had no effect on $G R$ reporter gene activity induced solely by dexamethasone (Fig. 8). Thus, this compound appears to specifically counteract the actions of vanadate on the GR.

A variety of reports support the notion that vanadate acts on the GR through tyrosine phosphorylation pathways. Examples include, the ability of tyrosine kinase-activating growth factors, such as EGF and IGF-1, to activate or potentiate the transactivation functions of androgen, progesterone, estrogen and GRs [30-33]. In their work with the androgen receptor, Reinikainen et al. [33] showed that androgen-dependent transcription activity in CV-1 and Hela cells could be increased, not only by EGF and IGF-1, but also by vanadate. Interestingly, although EGF did not alter the hormone-binding response of this receptor, vanadate treatment caused a significant reduction in this function that was reversible by treatment with genistein. Thus, the seemingly oppositional effects of vanadate on GR that we report are not unique to our cells or receptor, suggesting that the signal mechanism which mediates the vanadate stimulus is conserved, at least between human, simian and murine cells. That vanadate can actually stimulate tyrosine phosphorylation while modulating GR action has been shown by DeFranco and co-workers [34]. In this work, molybdate or vanadate treatment of permeabilized cells caused both an increase in overall tyrosine phosphorylation of proteins within the nucleus and stimulation of nuclear export of hormone-free receptors. Like the other studies mentioned, here too, the effects of vanadate were blocked by tyrosine kinase inhibitors (genistein and tyrphostin).

Although the above observations provide good circumstantial evidence for cross-talk of steroid receptors with tyrosine phosphorylation pathways, direct evidence of how this cross-talk leads to increased transcriptional activity has been lacking. In what may be the first evidence of this kind, Rowan et al. $[35,36]$ showed that steroid receptor co-activator-1 (SRC-1) contains several consensus sequences for phosphorylation by MAPK (ERK-1 and ERK-2), three of which were phosphorylated in vitro by ERK-2. More importantly, evidence was provided that potentiation of ligand-dependent, progesterone receptor-mediated transcription by EGF treatment of intact cells was mediated by SRC-1. As most studies on cross-talk between steroid receptors and phosphorylation signal pathways have failed to demonstrate altered phosphorylation of the receptor itself $[37,38]$, it is likely that control at the level of co-regulators may provide the basis for understanding, not only how vanadate is controlling GR action in our system, but also the general nature of transcription factor cross-talk with phosphorylation cascades.

\section{Materials and methods}

\subsection{Materials}

$\left[{ }^{3} \mathrm{H}\right]$ dexamethasone, $\left[{ }^{3} \mathrm{H}\right]$ dexamethasone 21-mesylate, $\left[{ }^{3} \mathrm{H}\right]$ acetate and $\left[{ }^{125} \mathrm{I}\right]$ conjugates of goat anti-mouse $\mathrm{IgG}$ and goat anti-rabbit IgG were obtained from ICN Radiochemicals. Sodium vanadate, sodium molybdate, dexamethasone, G418 (Geneticin) antibiotic, acetyl CoA synthetase, acetyl coenzyme A (CoA), ATP, Tris, Hepes, EDTA, protein A-Sepharose, DMEM powdered medium, horseradish peroxidase conjugates of goat anti-mouse and goat anti-rabbit IgG were from Sigma. Iron-supplemented newborn calf serum and dialyzed fetal bovine serum were from Hyclone. Immobilon PVDF membranes were obtained from Millipore Corp. Lipofectin reagent was obtained from BRL. The BuGR2 monoclonal antibody against GR was purchased from Affinity Bioreagents, Inc. The SC-7383 monoclonal antibody against phosphorylated (active) ERK was obtained from Santa Cruz Biotechnology, Inc.

The pMMTV-CAT plasmid contains the complete MMTV-long terminal repeat promoter (LTR) upstream of CAT [39]. Hormonally driven expression of CAT by this reporter is controlled by GREs residing within the LTR region [40]. The $\mathrm{pGRE}_{2} \mathrm{E} 1 \mathrm{~B}-\mathrm{CAT}$ minimal reporter is composed of two synthetic GREs derived from the tyrosine aminotransferase (TAT) promoter linked to the adenovirus E1B TATA sequence [23].

\subsection{Cell culture and vanadate treatment}

The various CAT reporter-expressing cells lines were established as previously described $[21,22]$. Briefly, mouse L929 cells were co-transfected with pSV2neo and a two-fold excess of pMMTV-CAT (LMCAT2 cells), or pGRE ${ }_{2}$ E1B-CAT (LGRECAT cells) using lipofectin as carrier. This was followed by selection for stably-transfected, cloned cell lines using G418 (Geneticin) antibiotic at $0.4 \mathrm{mg} / \mathrm{ml}$. Once established, all cell lines were grown in an atmosphere of $5 \% \mathrm{CO}_{2}$ at $37^{\circ} \mathrm{C}$ in DMEM containing $0.2 \mathrm{mg} / \mathrm{ml} \mathrm{G} 418$ and $10 \%$ iron-supplemented newborn calf serum. For all experiments, the newborn calf serum was stripped of endogenous steroids by extraction with dextran-coated charcoal. Most experiments were performed on cells that were at or near confluence; although similar results were obtained with sub-confluent cultures.

In the experiments involving sodium vanadate, the drug was typically added to the culture media for the indicated interval prior to hormone treatment, followed by washing and continued culture as indicated for each experiment. Vanadate was prepared according to the method of Gordon 
[16] by dissolving sodium orthovanadate $\left(\mathrm{Na}_{3} \mathrm{VO}_{4} \cdot n \mathrm{H}_{2} \mathrm{O}\right)$ to $500 \mathrm{mM}$ in sterile water and adjusting to approximately $\mathrm{pH}$ 10. To insure the presence of the active monomers, the vanadate stock solution was heated to boiling until the solution was clear.

\subsection{CAT assay}

Measurement of CAT enzyme activity was performed according to the method of Nordeen et al. [41] with minor modifications. In this assay, a reaction mixture containing acetyl CoA synthetase, $\left[{ }^{3} \mathrm{H}\right]$ sodium acetate, CoA and ATP is briefly preincubated to enzymatically generate labeled acetyl CoA A from CoA and labeled acetate. Acetylation of chloramphenicol was then initiated by adding cell lysate containing CAT enzyme. The reaction was stopped by extraction with cold benzene and $75 \%$ of the organic phase was counted. Cell lysates were prepared by sequential freezing and thawing in $0.25 \mathrm{M}$ Tris, $5 \mathrm{mM}$ EDTA ( $\mathrm{pH} 7.5$ ) and centrifugation at $14,000 \times \mathrm{g}$. Aliquots of lysate containing equal protein content were added to the enzymatic reaction mixtures.

\subsection{Cellular fractionation and immunoadsorption of $G R$}

Assay for subcellular localization of GR by fractionation was performed by two methods.

\subsubsection{Salt extraction method}

Replicate flasks $\left(75 \mathrm{~cm}^{2}\right)$ of LGRECAT cells subjected to a variety of vanadate and dexamethasone conditions were fractionated into cytosolic and nuclear portions by Dounce A homogenization in hypotonic buffer $(10 \mathrm{mM}$ Hepes, $1 \mathrm{mM}$ EDTA, pH 7.4). After centrifugation at $1000 \times g$ for $5 \mathrm{~min}$, the cytosolic fraction was saved and the nuclear pellet was washed two times by resuspension and pelleting in hypotonic buffer containing $250 \mathrm{mM}$ sucrose to separate nuclei from cellular membranes. Hypotonic buffer was then added to both the pellet and cytosolic fractions to a final volume of $0.5 \mathrm{ml}$. Each fraction was made $0.4 \mathrm{M}$ for $\mathrm{NaCl}$ by the addition of $0.5 \mathrm{ml}$ of a $0.8 \mathrm{M}$ stock solution and incubated on ice with occasional vortexing for $1 \mathrm{~h}$. After salt treatment, the nuclear pellets and cytosols were centrifuged at $16,000 \times g$ and the supernatants saved. BuGR2 anti-GR monoclonal antibody $(40 \mu \mathrm{l})$ was added to both the cytosolic and nuclear extract fractions and incubated on ice overnight. Each sample was then adsorbed in batch to protein A-Sepharose for $4 \mathrm{~h}$ at $4{ }^{\circ} \mathrm{C}$, washed three times with TEG buffer $(10 \mathrm{mM}$ TES, $1 \mathrm{mM}$ EDTA, $10 \%$ w/v glycerol, $50 \mathrm{mM} \mathrm{NaCl}, \mathrm{pH}$ 7.6) and the proteins extracted with $2 \times$ SDS sample buffer.

\subsubsection{SDS extraction method}

Cells were fractionated by Dounce homogenization, as described above. Cytosols and nuclear pellets were then solubilized and denatured by addition of SDS (final concentration $=2.5 \%$ ) and heating at $95^{\circ} \mathrm{C}$. After cooling and addition of Triton X-100 (final concentration $=2.5 \%$ ), each sample was immunoadsorbed with BuGR2 antibody, as described in the earlier sections.

\subsection{Gel electrophoresis and quantitative Western-blotting}

Samples were resolved by electrophoresis in $7 \%$ polyacrylamide SDS gels as described by Laemmli [42], followed by transfer to Imobilon ${ }^{\circledR}$ PVDF membranes. The relative amounts of GR and MAPK (ERK-1 and ERK-2) were determined via a quantitative Western-blotting technique previously described [43], involving incubation of the blots with primary antibody (BuGR2 for GR and SC-7383 antibody for active ERK-1 and ERK-2), followed by peroxidase- and $\left[{ }^{125} \mathrm{I}\right]$-conjugated counter antibodies. After color development, the blots were exposed to Kodak XAR-5 film with an intensifying screen at $-70^{\circ} \mathrm{C}$.

\subsection{Electrophoretic mobility shift assay (EMSA)}

Nuclear extracts from control and treated LGRE cells (one $75 \mathrm{~cm}^{2}$ flask each) were prepared as originally described by Dignam et al. [44], followed by measurement of protein content (BCA assay, Pierce). DNA mobility shift assays were performed as originally described by Sen and Baltimore [45]. The MMTV GRE [46] consists of base pairs from -191 to -159 of the MMTV-LTR and has the following sequence: 5'-GTT, TAT, GGT, TAC, AAA, CTG, TTC, TTA, AAA, CAA, GGA-3'. The GRE oligonucleotides were end-labeled with $\left[\gamma^{-32} \mathrm{P}\right]$ using $\mathrm{T} 4$-polynucleotide kinase. EMSA assays were performed by mixing $10 \mu \mathrm{g}$ of nuclear extract with $0.1 \mathrm{ng}(40,000 \mathrm{cpm})$ of ${ }^{32} \mathrm{P}$-labeled GRE oligonucleotides and $1 \mu \mathrm{g}$ of poly $(\mathrm{dI}-\mathrm{dC})$ in $1 \times$ gel shift buffer (10 mM Tris-HCl, pH 7.5, $50 \mathrm{mM} \mathrm{NaCl}, 1 \mathrm{mM}$ $\mathrm{MgCl}_{2}, 0.5 \mathrm{mM}$ EDTA, $0.5 \mathrm{mM}$ dithiothreitol, $4 \%$ glycerol) in a final volume of $20 \mu \mathrm{l}$. The reactions were carried out at room temperature for $30 \mathrm{~min}$, and protein-DNA complexes were analyzed on a $4 \%$ polyacrylamide gel in $0.5 \times \mathrm{TBE}$. The gels were run at $4{ }^{\circ} \mathrm{C}$ for $2 \mathrm{~h}$ at $175 \mathrm{~V}$ and were exposed to Kodak XAR-5 film with an intensifying screen at $-80^{\circ} \mathrm{C}$. The identity of GR was confirmed by addition of competitive unlabeled GRE oligonucleotide or by addition of monoclonal antibody (BuGR2) specific for GR.

\subsection{In vivo hormone-binding assay}

Cells were incubated with $10 \mathrm{nM}\left[{ }^{3} \mathrm{H}\right]$ dexamethasone for $2 \mathrm{~h}$ at $37^{\circ} \mathrm{C}$ in presence or absence of $10 \mu \mathrm{M}$ unlabeled dexamethasone. After three washes of the cells with Hank's buffered saline solution (HBSS, $\mathrm{pH}$ 7.4) to eliminate unbound ligand, cells were harvested in HBSS and centrifuged at $1000 \times g$ for $10 \mathrm{~min}$. The cell pellet was then rapidly frozen in dry ice/ethanol and stored at $-80^{\circ} \mathrm{C}$ for $30 \mathrm{~min}$, followed by resuspension in four volumes of whole-cell 
extract (WCE) buffer (20 mM Hepes pH 7.9, 25\% glycerol, $0.42 \mathrm{M} \mathrm{NaCl}, 1.5 \mathrm{mM} \mathrm{MgCl}_{2}, 0.2 \mathrm{mM}$ EDTA, $0.5 \mathrm{mM}$ PMS, $0.5 \mathrm{mM}$ DTT). After incubation on ice for $5 \mathrm{~min}$ and centrifugation at $100,000 \times g$ for $10 \mathrm{~min}$, the supernatants were collected and transferred to scintillation vials and counted. Steroid-binding capacities, measured in dpm, were normalized to $\mathrm{mg}$ of protein.

\section{Acknowledgements}

We thank Drs. Keith Schlender and Lee Faber (Medical College of Ohio) for insightful comments. This investigation was supported by a National Institutes of Health Grant (DK43867) to E.R. Sanchez.

\section{References}

[1] W.B. Pratt, D.O. Toft, Steroid receptor interactions with heat shock protein and immunophilin chaperones, Endocrinol. Rev. 18 (1997) 306-360.

[2] K.L. Leach, M.K. Dahmer, N.D. Hammond, J.J. Sando, W.B. Pratt, Molybdate inhibition of glucocorticoid receptor inactivation and transformation, J. Biol. Chem. 254 (1979) 11884-11890.

[3] W.A. McBlain, D.O. Toft, G. Shyamala, Transformation of mammary cytoplasmic glucocorticoid receptor under cell-free conditions, Biochemistry 20 (1981) 6790-6798.

[4] N. Murakami, T.M. Quattrociocchi, S.P. Healy, V.K. Moudgil, Effects of sodium tungstate on the nuclear uptake of glucocorticoid-receptor complex from rat liver, Arch. Biochem. Biophys. 214 (1982) 326334.

[5] W.A. McBlain, G. Shyamala, Heparin-mediated inactivation and transformation of mammary cytoplasmic glucocorticoid receptor, J. Steroid Biochem. 20 (1984) 1211-1220.

[6] D.B. Mendel, J.E. Bodwell, B. Gametchu, R.W. Harrison, A. Munck, Molybdate-stabilized non-activated glucocorticoid-receptor complexes contain a $90 \mathrm{kDa}$ non-steroid-binding phosphoprotein that is lost on activation, J. Biol. Chem. 261 (1986) 3758-3763.

[7] M. Denis, A.C. Wikstrom, J.A. Gustafsson, The molybdate-stabilized nonactivated glucocorticoid receptor contains a dimer of $\mathrm{Mr}$ 90,000 non-hormone-binding protein, J. Biol. Chem. 262 (1987) 11803-11806

[8] E.R. Sanchez, S. Meshinchi, W. Tienrungroj, M.J. Schlesinger, D.O. Toft, W.B. Pratt, Relationship of the $90 \mathrm{kDa}$ murine heat shock protein to the untransformed and transformed states of the $\mathrm{L}$ cell glucocorticoid receptor, J. Biol. Chem. 262 (1987) 6986-6991.

[9] P. Csermely, C.R. Kahn, The $90 \mathrm{kDa}$ heat shock protein (Hsp90) possesses an ATP-binding site and autophosphorylating activity, J. Biol. Chem. 266 (1991) 4943-4950.

[10] P. Csermely, J. Kajtar, M. Hollosi, G. Jalsovszky, S. Holly, C.R. Kahn, P. Gergely Jr., C. Soti, K. Mihaly, J. Somogyi, ATP induces a conformational change of the $90 \mathrm{kDa}$ heat shock protein (Hsp90), J. Biol. Chem. 268 (1993) 1901-1907.

[11] Z. Li, P.K. Srivastava, Tumor rejection antigen gp96/grp94 is an ATPase: implications for protein folding and antigen presentation, Embo. J. 12 (1993) 3143-3151.

[12] C. Soti, L. Radics, I. Yahara, P. Csermely, Interaction of vanadate oligomers and permolybdate with the $90 \mathrm{kDa}$ heat-shock protein, Hsp90, Eur. J. Biochem. 255 (1998) 611-617.

[13] B.M. Raaka, M. Finnerty, E. Sun, H.H. Samuels, Effects of molybdate on steroid receptors in intact $\mathrm{GH}_{1}$ cells: evidence for dissociation of an intracellular $10 \mathrm{~S}$ receptor oligomer prior to nuclear accumulation, J. Biol. Chem. 260 (1985) 14009-14015.
[14] J. Yang, D.B. DeFranco, Assessment of glucocorticoid receptor heat-shock protein 90 interactions in vivo during nucleocytoplasmic trafficking, Mol. Endocrinol. 10 (1996) 3-13.

[15] D.P. Li, S. Periyasamy, T.J. Jones, E.R. Sanchez, Heat and chemical shock potentiation of glucocorticoid receptor transactivation requires heat shock factor (HSF1) activity: modulation of HSF by vanadate and wortmannin, J. Biol. Chem. 275 (2000) 26058-26065.

[16] J.A. Gordon, Use of vanadate as protein-phosphotyrosine phosphatase inhibitor, Meth. Enzymol. 201 (1991) 477-482.

[17] H. Sun, C.H. Charles, L.F. Lau, N.K. Tonks, MKP1, an immediate early gene product, is a dual-specificity phosphatase that dephosphorylates MAP kinase in vivo, Cell 75 (1993) 487-493.

[18] Y. Ward, S. Gupta, P. Jensen, M. Wartmann, R.J. Davis, K. Kelly, Control of MAP kinase activation by the mitogen induced threonine/ tyrosine phosphatase PAC1, Nature 367 (1994) 651-654.

[19] B. Chu, F. Soncin, B.D. Price, M.A. Stevenson, S.K. Calderwood, Sequential phosphorylation by mitogen-activated protein kinase and glycogen synthase kinase 3 represses transcriptional activation by heat shock factor 1, J. Biol. Chem. 271 (1996) 30847-30857.

[20] J. Kim, A. Nueda, Y.H. Meng, W.S. Dynan, N.F. Mivechi, Analysis of the phosphorylation of human heat shock transcription factor 1 by MAP kinase family members, J. Cell. Biochem. 67 (1997) 43-54.

[21] D.P. Li, S. Li Calzi, E.R. Sanchez, Inhibition of heat shock factor activity prevents heat shock potentiation of glucocorticoid receptor-mediated gene expression, Cell Stress Chaperones 4 (1999) 223-234.

[22] E.R. Sanchez, J.L. Hu, S.J. Zhong, P. Shen, M.J. Green, P.R. Housley, Potentiation of glucocorticoid receptor-mediated gene expression by heat and chemical shock, Mol. Endocrinol. 8 (1994) 408-421.

[23] V.E. Allgood, R.H. Oakley, J.A. Cidlowski, Modulation by Vitamin $\mathrm{B}_{6}$ of glucocorticoid receptor-mediated gene expression requires transcription factors in addition to the glucocortcoid receptor, J. Biol. Chem. 268 (1993) 20870-20876.

[24] L. Whitesell, E.G. Mimnaugh, B. De Costa, C.E. Myers, L.M. Neckers, Inhibition of heat shock protein Hsp90-pp60v-src heteroprotein complex formation by benzoquinone ansamycins: essential role for stress proteins in oncogenic transformation, Proc. Natl. Acad. Sci. U.S.A. 91 (1994) 8324-8328.

[25] L. Whitesell, P. Cook, Stable and specific binding of heat shock protein 90 by geldanamycin disrupts glucocorticoid receptor function in intact cells, Mol. Endocrinol. 10 (1996) 705-712.

[26] E.H. Bresnick, E.R. Sanchez, W.B. Pratt, Relationship between glucocorticoid receptor steroid-binding capacity and association of the $\mathrm{Mr} 90,000$ heat shock protein with the unliganded receptor, J. Steroid Biochem. 30 (1988) 267-269.

[27] E.H. Bresnick, F.C. Dalman, E.R. Sanchez, W.B. Pratt, Evidence that the $90 \mathrm{kDa}$ heat shock protein is necessary for the steroid-binding conformation of the L cell glucocorticoid receptor, J. Biol. Chem. 264 (1989) 4992-4997.

[28] Y. Uehara, H. Fukazawa, Y. Murakami, S. Mizuno, Irreversible inhibition of pp60v-src tyrosine kinase activity by herbimycin A and its abrogation by sulfhydryl compounds, Biochem. Biophys. Res. Commun. 163 (1989) 803-809.

[29] R.S. Hegde, J. Zuo, R. Voellmy, W.J. Welch, Short circuiting stress protein expression via a tyrosine kinase inhibitor, herbimycin A, J. Cell. Physiol. 165 (1995) 186-200.

[30] S. Krusekopf, A. Chauchereau, E. Milgrom, D. Henderson, A.C. Cato, Co-operation of progestational steroids with epidermal growth factor in activation of gene expression in mammary tumor cells, J. Steroid Biochem. Mol. Biol. 40 (1991) 239-245.

[31] S.M. Aronica, B.S. Katzenellenbogen, Stimulation of estrogen receptor-mediated transcription and alteration in the phosphorylation state of the rat uterine estrogen receptor by estrogen, cyclic adenosine monophosphate, and insulin-like growth factor I, Mol. Endocrinol. 7 (1993) 743-752.

[32] S.K. Nordeen, M.L. Moyer, B.J. Bona, The coupling of multiple signal transduction pathways with steroid response mechanisms, Endocrinology 134 (1994) 1723-1732. 
[33] P. Reinikainen, J.J. Palvimo, O.A. Janne, Effects of mitogens on androgen receptor-mediated transactivation, Endocrinology 137 (1996) 4351-4357.

[34] J. Yang, J. Liu, D.B. DeFranco, Subnuclear trafficking of glucocorticoid receptors in vitro: chromatin recycling and nuclear export, J. Cell. Biol. 137 (1997) 523-538.

[35] B.G. Rowan, N. Garrison, N.L. Weigel, B.W. O’Malley, 8-Bromocyclic AMP induces phosphorylation of two sites in SRC-1 that facilitate ligand-independent activation of the chicken progesterone receptor and are critical for functional co-operation between SRC-1 and CREB binding protein, Mol. Cell. Biol. 20 (2000) 8720-8730.

[36] B.G. Rowan, N.L. Weigel, B.W. O’Malley, Phosphorylation of steroid receptor co-activator-1. Identification of the phosphorylation sites and phosphorylation through the mitogen-activated protein kinase pathway, J. Biol. Chem. 275 (2000) 4475-4483.

[37] P.N. Rangarajan, K. Umesono, R.M. Evans, Modulation of glucocorticoid receptor function by protein kinase A, Mol. Endocrinol. 6 (1992) 1451-1457.

[38] W. Bai, B.G. Rowan, V.E. Allgood, B.W. O’Malley, N.L. Weigel, Differential phosphorylation of chicken progesterone receptor in hormone-dependent and ligand-independent activation, J. Biol. Chem. 272 (1997) 10457-10463.

[39] M. Danielsen, J.P. Northrop, G.M. Ringold, The mouse glucocorticoid receptor: mapping of functional domains by cloning, sequencing and expression of wild-type and mutant receptor proteins, Embo. J. 5 (1986) 2513-2522.

[40] A.C. Cato, R. Miksicek, G. Schutz, J. Arnemann, M. Beato, The hormone regulatory element of mouse mammary tumour virus mediates progesterone induction, Embo. J. 5 (1986) 2237-2240.

[41] S.K. Nordeen, P.P.I. Green, D.M. Fowlkes, A rapid, sensitive, and inexpensive assay for chloramphenicol acetyltransferase, DNA 6 (1987) 173-178.

[42] U.K. Laemmli, Cleavage of structural proteins during the assembly of bacteriophage T4, Nature 227 (1970) 680-685.

[43] W. Tienrungroj, E.R. Sanchez, P.R. Housley, R.W. Harrison, W.B. Pratt, Glucocorticoid receptor phosphorylation, transformation, and DNA-binding, J. Biol. Chem. 262 (1987) 17342-17349.

[44] J.D. Dignam, R.M. Lebovitz, R.G. Roeder, Accurate transcription initiation by RNA polymerase II in a soluble extract from isolated mammalian nuclei, Nucl. Acids Res. 11 (1983) 1475-1489.

[45] R. Sen, D. Baltimore, Inducibility of kappa immunoglobulin enhancer-binding protein Nf-kappa B by a posttranslational mechanism, Cell 47 (1986) 921-928.

[46] F. Payvar, D. DeFranco, G.L. Firestone, B. Edgar, O. Wrange, S. Okret, J.A. Gustafsson, K.R. Yamamoto, Sequence-specific binding of glucocorticoid receptor to MTV DNA at sites within and upstream of the transcribed region, Cell 35 (1983) 381-392. 